Spectator sports are all the vogue, though nobody seriously contends that onlookers become much better putters or polevaulters by doing no more than trooping round and watching the experts. Courses, ward rounds, and the like which entail no active participation or clinical responsibility are rightly condemned. The criticisms are based on the canvassed views of B.P.A. members, which strongly favour active clinical work as the best form of postgraduate instruction. They also come down strongly in favour of unsalaried clinical assistantships (problems of finance are dealt with separately). The traditional British leaning towards practical, clinical skills provides a commendable foundation for overseas students. But the preventive and curative problems which will face them when they return to their own countries should be built into any teaching programme.

Can anything new be said about examinations and diplomas ? At least the report takes a binocular look at them, from the viewpoint of examiners as well as examinees. Not surprisingly, the motivation of candidates varies considerably, but nearly three-quarters of those sitting the M.R.C.P.Ed. and the Glasgow D.C.H. come from developing countries. Western experience is not always relevant to tropical conditions, and the report bluntly and properly condemns the fact that examinations may be "conducted by examiners, many of whom had had little or no recent experience of caring for children in malnourished and disease-ridden overseas communities."

In the United Kingdom there is a growing number of paediatricians who have been to developing countries not just as "visiting firemen" but to take an active part in dayto-day work. This applies particularly to Africa and India, which provide most of the data in the report. But its general recommendations are equally appropriate to other parts of the world. Their validity is already being confirmed on a small scale in many places which have academic connexions with Britain or, for example, in South Vietnam, where the Ministry of Overseas Development is sponsoring an imaginative five-year paediatric project. An essential feature is that the efforts of teachers and taught be reinforced by a two-way traffic of medical personnel-and ideas-between the home country and the others concerned.

The B.P.A. report rightly does not consider alternative approaches to improving the health of developing countries. Agriculture or population control or sanitation all offer tremendous scope, but they must be left to others. Paediatricians can have no doubts of what their endeavours could achieve. They have now this impressive blueprint for an exemplary reconstruction which should not be delayed.

\section{Sewage in the Sea}

The discharge of crude or partially treated sewage into coastal waters is often described in the lay press as a danger to health. If this is so it is important to define and quantitate the risk, particularly as summer visitors to coastal resorts already face the infective hazards associated with overcrowding and mass catering. How to prove a cause-and-effect relationship between a postulated hazard of the environment and a given disease has been discussed by A. Bradford Hill. ${ }^{1}$. The first requirement is to show that persons suffering from the disease have had a significantly greater exposure to the factor in question than an appropriate control group, as shown for example in linking cigarette smoking with lung cancer. Given this association, all the other available evidence is then weighed to assess whether the association is likely to be one of cause and effect. By these criteria, a Public Health Laboratory Service working party ${ }^{2}$ failed in a seven-year study to incriminate sewage-contaminated sea water as a cause of infective disease in Britain. The only sewage-borne illnesses it could reasonably ascribe to sea bathing were four cases of paratyphoid fever out of some 3,000 notified during the years in question. These four infections were associated with two beaches that were grossly polluted with solid faecal matter. The working party concluded that from the public health standpoint visually clean beaches were safe.

There is, then, no epidemiological evidence that sewagecontaminated sea water is a real risk to health. Furthermore, the superficially attractive argument that sewage contains viruses and must therefore be a danger to health is misleading. Various refined monitoring techniques have shown that sewage contains enteroviruses, but in small numbers and generally only when clinical infections are already occurring in the population concerned.

Whether or not a case can be made against coastal pollution as a hazard to health, there can be no dissent on its undesirability on aesthetic grounds. At many coastal towns, unsatisfactory outfalls, some of them even above low water mark, have become progressively overloaded as the population has increased. Two alternative solutions are being canvassed. One is to build outfalls long enough to ensure that the sewage effluent is diluted, dispersed, and purified without contaminating adjacent beaches. The other is to provide full treatment at inland sewage disposal works and then to discharge the effluent into a river or the sea. The problem is to decide which of these is the better method for a particular town. The effluent from a sewage works is visually clean but not sterile, and unless this also is taken some distance out to sea it may in fact cause greater bacterial contamination at the shore line than a well-sited sea outfall.

Until recent years the methods available for choosing the best point to site an outfall have been relatively crude. The Water Pollution Research Laboratory has studied this problem for several years. Its current report ${ }^{3}$ records encouraging progress in the development of methods for calculating the amount of contamination likely to result from the discharge of an effluent at any given point. Various radioactive and bacterial indicators have been used, and semiquantitative assessments can now be made on the basis of data from alternative sites. The laboratory has also continued its work on the lethal effects of sea-water and solar radiation on faecal organisms in the sea.

As the population increases in size and mobility the numbers of visitors to coastal towns will also rise. The eponymous gastrointestinal upsets associated with various resorts have received less attention than they deserve, though it has been suggested ${ }^{4}$ that they are similar to winter vomiting disease and are spread by close personal contact. Solutions must be found to the real and reputed public-health hazards of the seaside holiday if it is to retain its reputation as a health-restorer.

1 Hill, A. B., Proc. roy. Soc. Med., 1965, 58, 295

2 Public Health Laboratory Service, f. Hyg. (Lond.), 1959, 57, 435.

3 The Report of the Water Pollution Research Laboratory Steering Committee with the Report of the Director of Water Pollution Research, 1968. H.M.S.O., London.

4 Moors, B., Publ. Hlth Lond., 1962, 77, 28 